\title{
Systematic Dynamics Analysis of Land Reclamation in Mining area and Agricultural Economy Sustainable Development
}

\author{
Zhanhong Liu ${ }^{1, a}$, Baohua Zhou ${ }^{1, b^{*}}$ and Fang Dong ${ }^{1, c}$ \\ ${ }^{1}$ School of Resources and Environment, University of Jinan \\ astu_liuzh@126.com, bstu_zhoubh@ujn.edu.cn, cstu_dongf@ujn.edu.cn \\ *The corresponding author
}

\begin{abstract}
Keywords: Land reclamation; Agricultural economy; Sustainable development; Dynamics; Mining area

Abstract. In this article, the systems dynamics method is carried on in the field of Mining area land reclamation and the agricultural economy sustainable development, agricultural economy systems dynamics model in mining area is constructed based on the land amount of resources and the population capacity, and carries on the simulation examination to the model. Through compared the simulation results of three evolution tendency's model of Zaozhuang's agricultural economy system, obtains the conclusion that sustainable development is the most superior pattern in Zaozhuang agricultural economy system.
\end{abstract}

\section{Introduction}

The improper exploitation of coal resources has resulted in large-area surface subsidence, bringing in different levels of losses to the constructions, roads, railways, bridges and basic farmlands on the earth, as well as the contradiction between the population and the land, mining industry and the agriculture in the mine area, the mine land reclamation has played an important role in the sustainable development of agricultural economy in the mine area [1]. This paper studies the mine area by using system dynamics and taking the sustainable development of the economy in mine area as the target, starts from the micro structure of land-economy system and develops the basic feedback structure of the whole system, so as to better reflect the collaboration relationship between the mine land reclamation and the sustainable development of agricultural economy.

\section{System Structure}

One Basis of the System Structure -- Land Resources. There is no doubt that the coal exploitation destroys the land resources. As for different coal store conditions and exploitation methods, the coal resources exploitation brings different types and levels of destruction to the land resources. The underground mining has resulted in large-area surface subsidence, the earth surface in subsidence area cracks, sinks, causing the houses collapse, residents moving to other villages, and forming uneven bottomlands or river areas, so the farmland is destroyed and reduced. According to the estimation of experts, due to the issues like surface subsidence, mining production as well as the take up of factories and constructions, industrial production and deserts, the land resources reduces at a rate of $0.04 \%$. As for the agricultural and economic system, the land itself is an important production resource, which is the structural foundation of the dynamic system of agriculture and economy; the reduction of land resources directly affects the sustainable development of agriculture and economy [2].

Second Basis of System Structure - Population Capacity. The supply capacity of land resources directly affects the population capacity in the mine area, when the total population exceeds the limit of population capacity, the issues like the peasants losing land, recessive unemployment and revenue reduction would occur in the rural area. The population capacity adjusts the total population in mine area through the population migration variable in the population system negative feedback loop, and affects the employed population in various industries, and then affects 
the production values of various industries through production function. Meanwhile, the decision-maker could adjust the remaining population capacity by controlling the land reclamation rate, so as to solve the contradiction among urban miners in coal cities[3]. Therefore, the population capacity is the bridge that links the land resources and economic system, and is an indispensable factor in the system structure design in this paper.

Population Capacity Calculation Based on Land Resources. This paper identifies the population capacity based on land resources by calculating the maximum construction land and agriculture land in mine area. The maximum construction land uses the land-use planning as the standard, the construction area in ordinary mine area should not exceed the standard of 10,000 people/ $\mathrm{km}^{2}$ as regulated by the country [4]. That is:

$$
\text { Non - agriculture population capacity in coal cities }=\frac{\text { City land-use planning in the future }}{10,000 \text { people } / \mathrm{km}^{2}}
$$

Assume the agricultural acreage per capita of the agricultural population in the future remain unchanged, this assumption assure the income level of peasants in the future is at least the same as the current level. The calculation equation of agricultural population capacity is:

$\underline{\text { Agricultural population in the base year }}=\underline{\text { Agricultural population capacity in the future year }}$

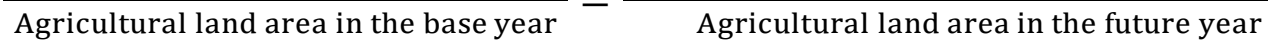

Where: Agricultural land area in mine $=$ Basic protected farmland area + wasteland area in mine * land reclamation rate -wasteland area in increased mines, the land reclamation rate in mine reflects the degree of reclamation and comprehensive utilization of the left land resources after mine exploitation, its calculation equation is:

$$
\text { Mine land reclamation rate }=\frac{\text { Mine wasteland reclamation area }}{\text { Total mine wasteland area }} \times 100 \%
$$

\section{Model structure Design}

Sustainable Development System Structure of Agriculture and Economy in Mine. The sustainable development system dynamics model of agriculture and economy in mine mainly consists of three models of land, people and economy, which are closely connected and interact with each other. Besides the small feedback within individual models, big feedbacks across models are formed, so as to develop a multi-level feedback system, reflecting the complexity features of land reclamation and economic sustainable development system[5].

(1) Coal_—and resources model. This model takes the coal exploitation amount in mine as the state variable, uses the negative feedback (that is, resources exploitation -- exploited mine resources -- remaining exploitation amount -- resources exploitation) to dynamically simulate the increased area of wasteland in mine, and simulate the dynamic changes of the agriculture land by setting reclamation rate and calculating land reclamation area. When the remaining exploitation amount is zero, the coal resources exploitation speed is zero, and then the loop disappears.

(2) Population model_ - This model is developed according to the population capacity based on the land resources, uses a negative feedback (that is, population -- left population capacity -population migration increase - population) and a positive feedback (population -- population increase - population) to simulate the dynamic variation rule of population and employed population under the condition of changing land resources.

(3) Economy model_ This model uses the production function to link the variables like employed population, science and technology development condition, investment in the fixed asset of primary industry together and simulates the total production value of the primary industry. Since the land is an important production resource in agriculture production, land reclamation is the investment for this fixed asset - land, which takes a bigger proportion in the agriculture fixed asset investment in mine.

(4) Across-model feedback loop_-There is complicated interaction between population, land resource, agricultural economy models, and then form a cross-system feedback loop. The main 
feedback loop is: remaining population capacity - reclamation rate -- reclamation area -- wasteland area in mine - agricultural land area -- population capacity -- left population capacity, the loop means the remaining population capacity reduces, the reclamation rate increases, the reclamation area increases, reclamation area and wasteland area in mine reduces, agricultural land area increases, population capacity increases, remaining population capacity increases, it is positive feedback.

The Mixed Chart of Land Reclamation as well as Agricultural and Economic Sustainable Development System in Coal Cities

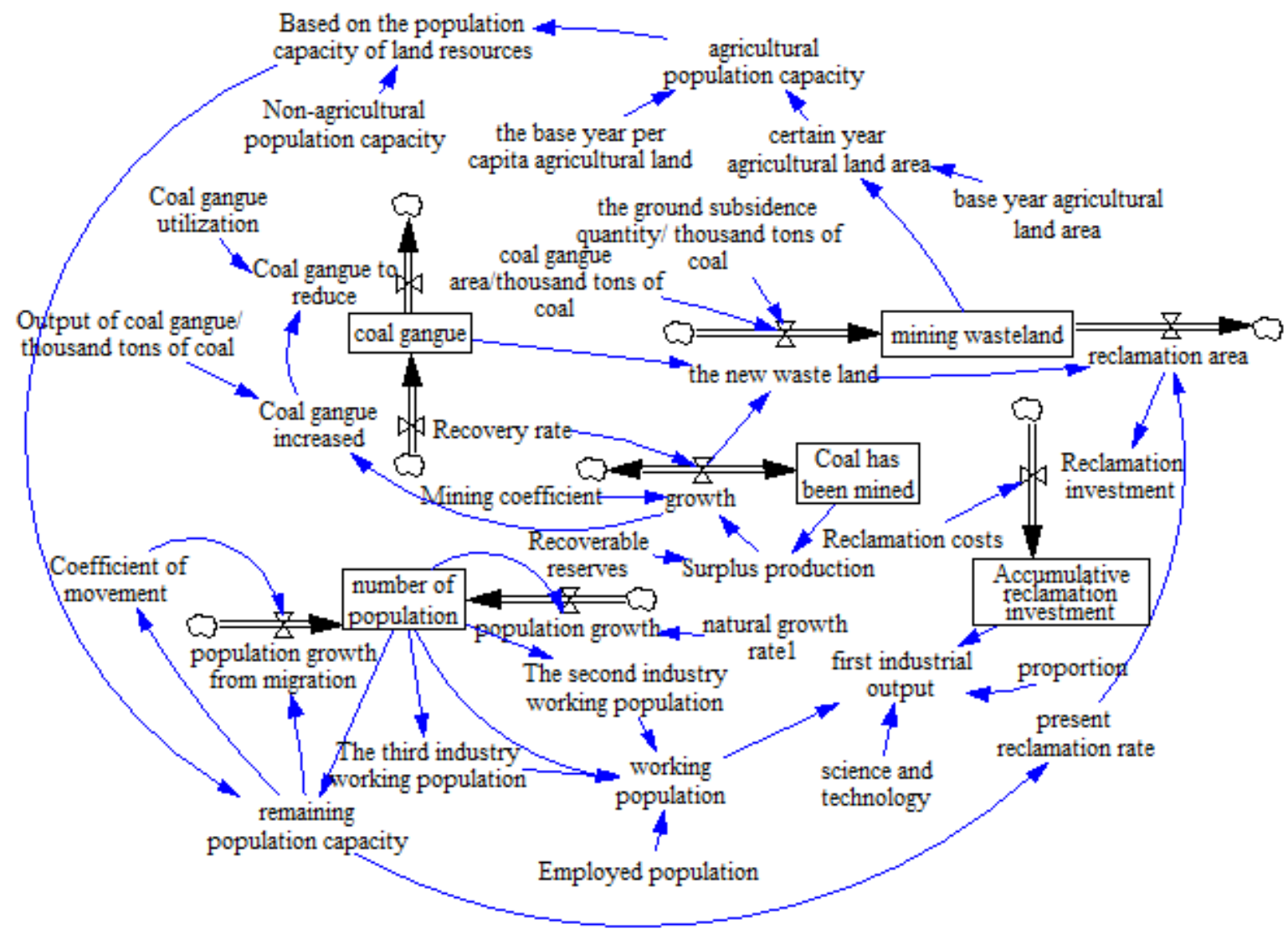

Figure 1. The relation land - population - economic in mining area

\section{Functional Relationship among Model Variables and Determination of Parameters}

The model focuses on simulating the changes of land resources and population capacity, and taking them as the limit condition for the agriculture and economy sustainable development in mine. Simulate the evolution and development features of agricultural and economic system in mine under this limit condition. According to the modeling procedure of system dynamics and on the basis of comprehensive study and statistics materials collection, analyze the relationship between model variables, by referring to the developed equations and parameters which already have research achievements, separately build relevant parameters and models, and finally build a system dynamics model of agricultural and an economic sustainable development in mine.

The model parameters could be identified by the following three ways $[6,7,8]$ :

First, calculate exploitation coefficient, population natural growth rate and migration rate with arithmetic mean method.

Second, calculate the employed population in the second and third industries through trend extrapolation.

Third, it is the regression analysis method. Many kinds of regression methods have been used in 
the model to identify the relationship between parameters, for example, use multivariate nonlinear regression to identify the production value of the first industry.

After identifying the model parameters through above methods, use the calculation tool -VENSIM PLE to complete simulation calculation, and obtain the predictive index value that evaluates each index at each time-point during the simulation period in mine. To verify the effectiveness of models, verify the calculation result of models.

(1) Consistency verification between model behavior and actual system. The paper has limited the time to the year $2000-2020$, and adopts the method of forwarding the calculation start time. Take the land reclamation and agricultural-economical system of Zaozhuang city in 2000 as the base period, use the data before 2014 for the verification of models and parameters, and use the data after 2014 for prediction. Judge the operation effect of models by comparing the simulation values and the actual values.

Table 1 Circumstances table about kinetic model simulation fitting with the historical data

\begin{tabular}{|c|c|c|c|c|c|c|}
\hline \multirow[b]{2}{*}{ Variables } & \multicolumn{4}{|c|}{2000} & \multicolumn{2}{|c|}{2005} \\
\hline & $\begin{array}{l}\text { Actual } \\
\text { Value }\end{array}$ & $\begin{array}{l}\text { Simulation } \\
\text { Value }\end{array}$ & Error $(\%)$ & $\begin{array}{l}\text { Actual } \\
\text { Value }\end{array}$ & $\begin{array}{l}\text { Simulation } \\
\text { Value }\end{array}$ & Error $(\%)$ \\
\hline $\begin{array}{c}\text { Population (Ten Thousand } \\
\text { People ) }\end{array}$ & 357.9949 & 360.9 & $0.81 \%$ & 367.2695 & 376.4 & $2.49 \%$ \\
\hline $\begin{array}{c}\text { Annual Coal Mining } \\
\text { Amount(Ten Thousand Ton) }\end{array}$ & 1808.00 & 1875.4 & $3.73 \%$ & 3045.3 & 2925.55 & $-3.93 \%$ \\
\hline $\begin{array}{l}\text { Output value of primary } \\
\text { industry } \\
\text { (Hundred Million } \\
\text { Yuan) })\end{array}$ & 41.68 & 41.55 & $-0.31 \%$ & 62.49 & 64.057 & $2.51 \%$ \\
\hline \multirow[b]{2}{*}{ Variables } & \multicolumn{4}{|c|}{2010} & \multicolumn{2}{|c|}{2014} \\
\hline & $\begin{array}{l}\text { Actual } \\
\text { Value }\end{array}$ & $\begin{array}{l}\text { Simulation } \\
\text { Value }\end{array}$ & Error $(\%)$ & $\begin{array}{l}\text { Actual } \\
\text { Value }\end{array}$ & $\begin{array}{l}\text { Simulation } \\
\text { Value }\end{array}$ & Error $(\%)$ \\
\hline $\begin{array}{c}\text { Population (Ten Thousand } \\
\text { People ) }\end{array}$ & 391.4 & 394.6 & $0.82 \%$ & 401.33 & 396.4 & $-1.23 \%$ \\
\hline $\begin{array}{c}\text { Annual Coal Mining } \\
\text { Amount(Ten Thousand Ton) }\end{array}$ & 3152.22 & 3004.4 & $-4.67 \%$ & 3274.71 & 3198.2 & $-2.33 \%$ \\
\hline $\begin{array}{l}\text { Output value of primary } \\
\text { industry } \\
\text { (Hundred Million } \\
\text { Yuan) })\end{array}$ & 117.56 & 121.3 & $3.18 \%$ & 156.09 & 147.9 & $-5.25 \%$ \\
\hline
\end{tabular}

According to the result of verification, the relative difference between the indicator simulation value and actual value in mine of Zaozhuang is within the range of $-5 \%-5 \%$. In general, the system model truly simulates the system structure and condition, the simulation accuracy is relative high, and could be used as the simulation and prediction method for the land reclamation and agricultural-economic system sustainable development in mine.

(2) Verification for the sensitivity of model system. It is found that the behavior of model is greatly affected by part of parameters like utilization ratio of coal gangue, recovery ratio, land reclamation rate, and through the regulation for system parameters, it is possible to simulate the evolution trend of agricultural-economic system in coal cities.

(3) Verification for the suitability and consistency of model structure. In the modeling process, use the equation verification and dimension verification functions of Vensim PLE software to conduct structure consistency verification. Meanwhile, by referring to the models in the other papers, establish the feedback structure and dynamics equation ${ }^{i}$ that comply with the 
agricultural-economic system characteristics in mine. The parameters in models could be directly obtained from historical statistics data or by referring to relevant materials.

\section{System Dynamics Analysis for the Agricultural-Economic Development in Mine of Zaozhuang}

According to the simulation test, the sensitive variables like coal recovery rate affect the behavior and evolution trend of agricultural-economic system, therefore, by regulating and testing the sensitive variable parameters and using various combination of parameters, simulate the trend and direction of system development [6]. In this paper, simulate three mine development models by regulating the sensitive parameters of land- agricultural and economic system in mine: Non-sustainable development model A, High-speed economic growth model B, Sustainable development model $\mathrm{C}[7,8]$. The sensitive parameters of three models are shown in table 2 . The changes of sensitive parameters bring obvious changes to the city population, land resources and agricultural-economic development in Zaozhuang. For details, please refer to table 3.

Table 2 Sensitive parameters of three models

\begin{tabular}{l|ccc|c|ccc}
\hline & \multicolumn{3}{|c|}{ Parameter Value } & \multicolumn{3}{c}{ Parameter Value } \\
\cline { 2 - 4 } \cline { 5 - 6 } & A & B & C & & A & B & C \\
\hline $\begin{array}{l}\text { Reclamation } \\
\text { Rate }\end{array}$ & 0.2 & 0.6 & 1 & $\begin{array}{c}\text { Coal Mining } \\
\text { Coefficient }\end{array}$ & 0.08 & 0.05 & 0.03 \\
\hline $\begin{array}{l}\text { Recovery } \\
\text { Rate }\end{array}$ & 0.35 & 0.6 & 0.85 & $\begin{array}{c}\text { Gangue Use } \\
\text { Rate }\end{array}$ & 0.2 & 0.6 & 1 \\
\hline
\end{tabular}

Table 3 Comparison of agricultural economic system developmental indicators in Zaozhuang mining area under three models

\begin{tabular}{|c|c|c|c|c|c|c|c|c|c|c|}
\hline \multirow{2}{*}{ Variables } & \multirow{2}{*}{2000} & \multicolumn{3}{|c|}{2007} & \multicolumn{2}{|c|}{2015} & \multirow[b]{2}{*}{$\mathrm{C}$} & \multicolumn{3}{|c|}{2020} \\
\hline & & A & B & $\mathrm{C}$ & A & B & & A & B & $\mathrm{C}$ \\
\hline $\begin{array}{l}\text { Output value of primary } \\
\text { industry (Hundred } \\
\text { Million Yuan)) }\end{array}$ & 36.9 & 63 & 82.34 & 96.035 & 70.41 & 131.9 & 209.2 & 67.15 & 133.27 & 227.4 \\
\hline $\begin{array}{c}\text { Population capacity(Ten } \\
\text { Thousand People) }\end{array}$ & 362.56 & 373.7 & 390.7 & 395.3 & 365.5 & 386.6 & 395.3 & 356.4 & 384.5 & 395.3 \\
\hline $\begin{array}{l}\text { The population(Ten } \\
\text { Thousand People) }\end{array}$ & 354.53 & 376.58 & 381.59 & 381.93 & 369.92 & 390.14 & 398.42 & 361.29 & 387.93 & 398.42 \\
\hline $\begin{array}{l}\text { Agricultural land area } \\
\qquad(\mathrm{Ha})\end{array}$ & 186500 & 178018 & 182844 & 186500 & 171805 & 179641 & 186500 & 168435 & 177953 & 186500 \\
\hline $\begin{array}{c}\text { Coal can be mined(Ten } \\
\text { Thousand Ton) }\end{array}$ & 124641 & 96529 & 100160 & 105836 & 76911 & 79150 & 86077 & 66730 & 68320 & 75648 \\
\hline
\end{tabular}

Agricultural and economic system changing trend under the influence of three models. Analyze the changing trend of the first industry production value in mine of Zaozhuang under the influence of three development models, and the characters are shown as below.

(1) The first industry production value in the non-sustainable development model has the trend of rise first and then fall. The production value increase at earlier stage is caused by the increase of fixed asset amount in the first industry, though the amount of land resources reduces, the population 
capacity held by the land is still bigger than the total population, and there is obvious agricultural economic growth. The continuous increase of wasteland in mine in the later period quickly reduces the farmland area in mine, and then the agricultural production loses its relied land resources, so there is economic recession.

(2) In the process of variable determination, the sustainable development model has set the coal gangue utilization rate and land reclamation rate as 1 , when the per-capita agricultural land and urban land area remain unchanged, the land resources could be maintained at a certain level. The first industry production value curve in Fig. 2 has the shape of "S", it is because the model has taken the scientific and technological level which is used as production factor as the constant, the limitation of scientific and technological development is obvious.

(3) Compare and analyze the three models, the sustainable development model has provided land resources guarantee for the sustainable development of agricultural economy, its production value is the highest, the second is the high-speed economic growth model, the last one is the non-sustainable development model.

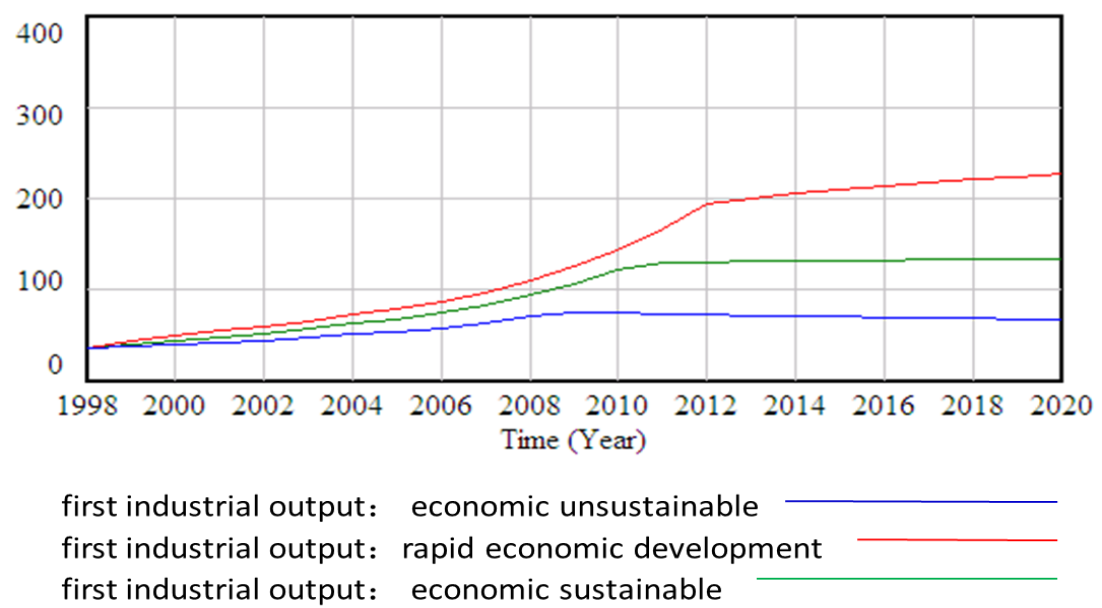

Figure 2. Trends of economic capacity (ten thousand yuan )

The changing trend of land resources under the influence of three models. The difference in sensitive parameters like coal gangue utilization rate, land reclamation rate in the three development models has caused bigger difference in the agricultural land areas. The sustainable development model takes full utilization of coal gangue; the land reclamation rate is 1 , so that the agricultural land area remains changed. The coal exploitation in high-speed economic growth model is a little higher than the sustainable development model, while the coal gangue utilization rate and land reclamation rate is lower than the coordinated development model, in the same way, the values of sensitive parameters in non-sustainable economic model are the smallest, therefore the agricultural land area decreases gradually, while the decreasing extend in non-sustainable economic model is larger.

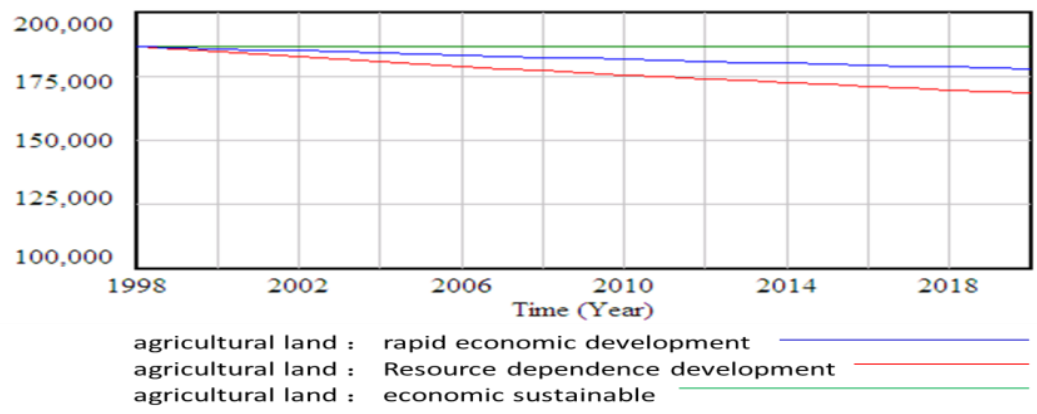

Figure 3. Trends of agricultural land change 
The Changing Trend of Population System under the Influence of Three Models. The population capacity in mine of Zaozhuang is decided by the land capacity. The population natural growth rate is hard to change within a period, the migration population growth, which is limited by the remaining population capacity, is the variable that frequently changes. When the number of population exceeds the population capacity, the population natural growth continues under the inertia force, while the population migration growth is negative value, so as to offset the population natural growth. As for the non-sustainable development model, the economy capacity and land capacity is small and has the trend of decreasing, the migration population is larger, the total population reaches the peak in 2008 under the natural growth force, and then decrease. In the same way, the bigger land capacity in high-speed economic development model and sustainable development model attracts immigration of large amount of employed population, and the population base increases dramatically on this basis, the population natural growth continues, but the land resources limit the migration population growth, and then keep the final number population at a steady level.

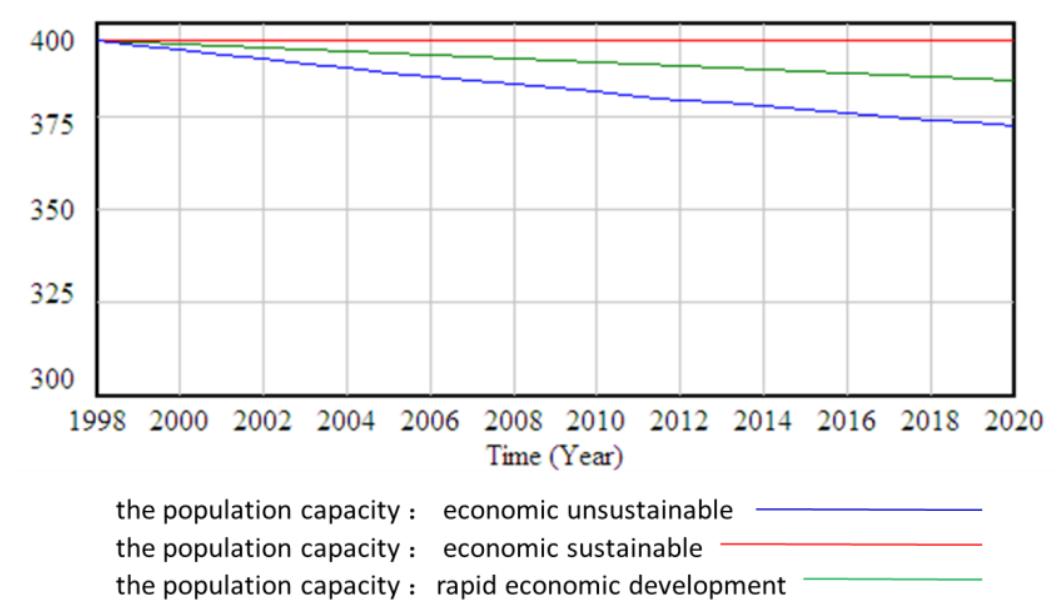

Figure 4. Trends of population capacity (ten thousand people)

\section{Conclusion}

By analyzing the evolution trend of three models like non-sustainable economic model, high-speed economic development model and sustainable development model in different sub-systems in mine of Zaozhuang, it is possible to summarize the several points as below:

(1) Non-sustainable development model. The non-renewal of coal resources and limitation of land resources means this development model would cause the land resources exhaustion, economic recession, population reduction, environment deterioration, so this model is inadvisable.

(2) High-speed economic development model takes economic development as the guide, emphasizes high efficient utilization of resources and environment protection on some extent, but the economic sub-system is inharmonious with the resources and population sub-systems, then resulting in the vibration and instability in economic development.

(3) The sustainable development model emphasizes both the economic development and environment protection, as well as efficient utilization of resources, developing a positive circle of land-agricultural economic system harmonious development, which is the first choice of mine development model $[9,10]$.

\section{Acknowledgements}

This paper is derived from the social science fund of University of Jinan: X1146. 


\section{References}

[1] X.Z. Guo, J. Pan and G.G. Wu: Irrig. and Drain, Vol.64(2015), No.1 , p.139.

[2] J.C. Xue,C. Song. Research of Soil and Water Conservation, Vol. 18(2011), No.6 , p.204.(In Chinese)

[3] Forrest,J.W: Principles of systems.Camb.Ma (Wright-Allen press lne.1968).

[4] Z.H.Liu: Energy Procedia-- IACEED2010(Jinan,2010), Vol. 5( 2011),p.2486

[5] Z.H.Liu: Energy Procedia-- IACEED2010(Jinan,2010), Vol. 5( 2011),p.1797

[6] Y.N. Huang: Non-linear Dynamics Introduction (Peking University Press.2010). (In Chinese)

[7] Forrest,J.W: Urban Dynamics.Camb.Ma ( MIT press,Tenth printing, 1969).

[8] Forrest,J.W:World Dynamies.Camb.Ma (Wright-Allen press Ine.1973)

[9] W. Xiao , Z.Q. Hu ,And Y.H. Fu: International Journal of Coal Science \& Technology, Vol. 1(2014), p.177

[10]C.C. Hu, C.Chen and Y. Yu: Advanced Materials Research, Vol.2480(2013).p. 4991. 